\title{
The pursuit of satisfaction: Variation in satisfaction with bus transit service among riders with encumbrances and riders with disabilities using a large-scale survey from London, UK
}

\author{
David Verbich \\ School of Urban Planning \\ Faculty of Engineering \\ McGill University \\ Room 401, Macdonald-Harrington Bldg. \\ 815, rue Sherbrooke Ouest \\ Montreal QC Canada \\ H3A 0C2 \\ david.verbich@,mail.mcgill.ca
Ahmed El-Geneidy (corresponding author)
School of Urban Planning
Faculty of Engineering
McGill University
Room 401, Macdonald-Harrington Bldg.
815 , rue Sherbrooke Ouest
Montreal QC Canada
H3A 0C2

Tel: 514-398-8742

Fax: 514-398-8376

ahmed.elgeneidy@mcgill.ca

\section{November 2015}

For citation please use: Verbich, D. \& El-Geneidy, A. (2016). The pursuit of satisfaction: Variation in satisfaction with bus transit service among riders with encumbrances and riders with disabilities using a large-scale survey from London, UK. Transport Policy, 47, 64-71. 


\section{ABSTRACT}

2 To retain and grow ridership, transit agencies continuously survey riders to learn how to improve

3 services and understand what leads to rider satisfaction. Nevertheless, transit riders are not a

4 homogeneous entity and understanding the distinctions between transit riders can help transit

5 agencies in their efforts to provide satisfactory service to retain existing riders and attract new

6 ones. To uncover how diverse aspects of bus services can differentially impact satisfaction of

7 different riders, we use data from a large-scale, multiyear bus satisfaction survey from London,

8 UK. Specifically, we model satisfaction using logistic regressions to learn how encumbered

9 riders and riders with physical disabilities value different features of bus services compared to

10 other types of riders. For riders traveling with large items, shopping bags, or children, we find

11 that satisfaction depends on the presence and condition of a bus shelter and the availability of a

12 seat. Satisfaction of riders with disabilities depends on information availability at the bus stop, as

13 well as trip speed and reliability. Our findings indicate that improving waiting area conditions

14 and providing information at the stop can increase the satisfaction of riders with encumbrances

15 and disabilities, respectively. Findings from this paper can be of benefit to transit planners and

16 policy makers as it offers new insights about the determinants of satisfaction of two groups of

17 bus riders not often considered in the public transport literature. 


\section{INTRODUCTION}

2 Not only must transit agencies operate effective and viable transit networks, but agencies must

3 also understand the needs and satisfaction of riders with the transit system (Koushki, Al-Saleh, \&

4 Al-Lumaia, 2003). Satisfying existing riders and attracting new ones is central to a healthy transit 5 system, as is it helps build loyalty to retain riders (Imaz, Nurul Habib, Shalaby, \& Idris, 2015).

What will satisfy a transit rider? The answer to this seemingly straightforward question is complex; satisfaction with transit depends on many different components, from safety to

8 courteous staff to punctual and reliable services (Board, 1999; Eboli \& Mazzulla, 2007, 2011;

9 Weinstein, 2000). Nonetheless, not all riders value the same features of transit services, so

10 agencies need to clarify distinctions, such as the expectations of different groups of riders. A

11 substantial amount of research is aimed at uncovering different segments of riders, such as 12 captive and choice riders (Krizek \& El-Geneidy, 2007; Shiftan, Outwater, \& Zhou, 2008; Zhao,

13 Webb, \& Shah, 2014), and newer work has parsed riders into even more diverse groups, such as

14 captive-by-choice, riders with access to a car, but choose to use transit (van Lierop \& El-

15 Geneidy, 2014).

Apart from more obvious demographic differences based on age and income of riders, or

17 frequency of use, other population segments have received less attention. Often overlooked are

18 riders with physical disabilities who use regular services instead of adapted dial-a-ride services,

19 or riders encumbered by shopping bags or small children. The satisfaction of different groups of

20 riders can be based on different features and if a transit agency understands how riders with

21 disabilities or encumbrances value features of bus services, then policies can be targeted to

22 increase their satisfaction (Delbosc \& Currie, 2011). In the present paper, we studied a large-

23 scale, multiyear bus customer satisfaction survey from London, UK, to uncover how these

24 groups of riders value different components of a bus service and compare them to other riders.

25 This in turn will help to generate policies that will be effective in increasing satisfaction among 26 all users.

27 The paper starts with a literature review on transit customer satisfaction and vulnerable 28 populations' satisfaction with transit. Second, we detail the survey and methods used in the 29 analyses. Third, we describe the results of the logistic model regressions based on three

30 subgroups of defined bus riders. Lastly, we discuss our findings and potential policy

31 implications. 
2 LITERATURE REVIEW

3 Satisfaction and Public Transit

4 A large body of research has developed to uncover the service attributes that lead to public

5 transit riders' satisfaction. An early study of rapid transit in the San Francisco Bay Area analyzed customer satisfaction and found that information and service timeliness were most important to customers (Weinstein, 2000). Studying satisfaction with the New York City subway with

8 structural equation modeling (SEM) determined that station cleanliness, predictability or reliability, and personal safety had large direct and indirect impacts on satisfaction (Stuart,

11 factors can impact satisfaction in explicit ways, as well as how factors may work together to

12 indirectly influence satisfaction. A SEM study of satisfaction of a bus route frequented by

13 university students in Italy found that service reliability, comfort, and network design impacted

14 overall satisfaction (Eboli \& Mazzulla, 2007). Similarly, a study of transit satisfaction in

15 Calgary, Canada discovered that reliability and convenience were valued more than ride comfort,

16 suggesting that transit providers should focus on reducing multimodal transfers and improving

17 network connectivity (Habib, Kattan, \& Islam, 2011). A recent SEM study of perceived service

18 quality discovered that service, comfort, and safety are important service attributes. Moreover,

19 these three attributes were affected by other factors as well. For example, satisfaction with speed

20 and frequency impacted service satisfaction to a greater degree than satisfaction with stop

21 proximity and transit fares (de Oña, de Oña, Eboli, \& Mazzulla, 2013).

Nevertheless, other studies have found that safety and ease of transit access were more

23 important for satisfaction compared to information and reliability (Iseki \& Smart, 2012).

24 Interestingly, Iseki and Smart (2012) found that subtleties arise when analyzing men and women

25 separately, or frequent riders, for example. This finding suggests that individuals have different

26 requirements for satisfaction with transit. Regardless, components such as waiting time,

27 reliability, journey time, comfort, safety, and driver behavior all influence rider satisfaction,

28 although the degree to which each component contributes to overall satisfaction seems to vary,

29 not only between cities, but between groups of riders as well. Circumstances beyond the control

30 of transit agencies can also influence customer satisfaction with transit, as new work suggests

31 that life satisfaction and personal disposition can significantly explain satisfaction with transit 
1 service (Carrel, Mishalani, Sengupta, \& Walker, 2015; Lai \& Chen, 2011; St-Louis, Manaugh,

2 van Lierop, \& El-Geneidy, 2014).

4 Rider Segmentation in Transit and Vulnerable Populations

5 A recent of stream of investigation into transit satisfaction aims at discovering whether personal characteristics modify an individual's use and evaluation of transit services. Two types of riders are commonly identified as captive and choice riders. Captive riders have no other option but to use transit for travel, while choice riders typically have access to a car but choose to use transit for specific trips (Jin, Beimborn, \& Greenwald, 2005). Krizek and El-Geneidy (2007) found that these definitions can be extended to regular and irregular users depending on frequency of use,

11 and these four types of users value different aspects of transit service. Recent work based on two

12 Canadian cities uncovered a previously uncategorized type of rider-captive-by-choice (van

13 Lierop \& El-Geneidy, 2014). These transit users have car access, but yet choose to use transit for 14 many reasons, including environmental awareness.

Another approach is to analyze pre-defined subgroups and their preferences and satisfaction with transit service. In a study of satisfaction in the San Francisco Bay Area,

17 occasional riders and those with low-incomes were less concerned with daytime safety than

18 higher-income earners (Iseki \& Smart, 2012). Gender differences are less clear, such as the 19 importance of on-time reliability or other factors (Carrel, Mishalani, et al., 2015; Iseki \& Smart, 20 2012). More recent work in the Bay Area using vehicle tracking and multiday travel satisfaction 21 surveys found that age was an important determinant of satisfaction with in-vehicle transit time,

22 while income had no effect on satisfaction with in-vehicle transit time, waiting time, transferring, 23 or reliability (Carrel, Mishalani, et al., 2015). However, less work has focused on vulnerable 24 populations and their satisfaction with transit.

Using a household travel survey in Melbourne, Australia, Delbosc and Currie (2011)

27 residents with impairments or social vulnerabilities that hindered their ability to use transit. In 28 particular, impaired residents make fewer trips and describe feelings of social exclusion because 29 they have difficulty reaching transit stations and boarding/alighting vehicles (Delbosc \& Currie, 30 2011). People with sensory disabilities, including hearing and visual impairments, who use 31 public transit require particular attention (Hunter-Zaworski \& Hron, 1999), especially in terms of 
1 bus design and accessibility (Bareria, D’Souza, Lenker, Paquet, \& Steinfeld, 2012). In addition,

2 people with mobility impairments who use public transit face physical difficulties (Delbosc \&

3 Currie, 2011; Hunter-Zaworski \& Zaworski, 1999; Lubin \& Deka, 2012). Instead, they may opt

4 to use dial-a-ride services, although overall satisfaction depends on numerous criteria (Paquette,

5 Cordeau, \& Laporte, 2009) and has been demonstrated to be low (Denson, 2000). Furthermore,

6 dial-a-ride services are typically costly for transit agencies (Marković, Milinković, Schonfeld, \&

7 Drobnjak, 2013). Access to dial-a-ride services may not be feasible for all individuals with

8 disabilities given rather stringent qualification criteria (London, n.d.-b), and may be inconvenient

9 for some riders in terms of the need to schedule journeys in advance (MTA, n.d.). As such, the

10 service characteristics of regular transit that may satisfy disabled riders have not been studied. In

11 addition, riders carrying small children or babies, as well as riders using transit for shopping and

12 carrying bags may require special attention to be satisfied and to keep using transit. This is

13 particularly relevant for captive riders using transit for errands.

\section{DATA AND METHODOLOGY}

\section{Context and Survey Overview}

17 Transport for London (TfL) provides transit services in the Greater London, UK area, a densely

18 populated urban area with a population of nearly 9 million people. TfL services include the

19 London Underground, London Overground, and London Buses. Although TfL sets bus routes

20 and schedules, the operation of individual bus routes is the responsibility of private bus

21 operators, and contracts are awarded through a competitive tender process. Over 90\% of

22 Londoners live within 400 meters of a bus stop, and nearly 9,000 vehicles serve 675 routes

23 (London, n.d.-a).

24 The dataset analyzed in this article comes from a five-year customer satisfaction survey

25 administered by trained interviewers as intercept interviews to passengers alighting at bus stops

26 across the Greater London area. After screening the interviewee based on potential employment

27 or relation to a TfL employee, and whether the respondent is over 16 years of age, the

28 interviewer proceeds with questions pertaining to the bus route from which the respondent just

29 alighted. The respondent is initially asked how much time they spent on the bus, and then

30 specifically their overall satisfaction with the entire trip starting at the boarding bus stop. In this 
1 study, we use overall trip satisfaction, which was rated from 0 to 10 , ranging from extremely dissatisfied to extremely satisfied, as the dependent variable in our models.

After asking overall satisfaction, a number of questions delve into different characteristics of the trip, including satisfaction with the bus stop/shelter (if any), the bus

5 condition (exterior and interior), the ride quality, as well as information availability (outside and inside the bus). Other questions pertain to service characteristics, like reliability, satisfaction with time waited and total journey time, journey purpose, as well as personal characteristics such as

8 gender, age, race, and regularity of use. Because this survey took place over five years, questions were modified, and new questions were added throughout the years. For consistency in our models, we mostly used questions that were asked throughout the five-year period to have as

11 large a sample as possible. For instance, household income was queried beginning only in 2014, 12 and therefore reduced the sample size considerably to about 5,000 respondents. We ran pilot 13 models including household income and found that it was not an explanatory variable in our 14 models of overall satisfaction (data not shown).

\section{Data Preparation}

17 The initial dataset included 65,506 respondents from 2010 to 2015 . We included only

18 respondents living in London and respondents that were not visitors to limit our dataset to

19 Londoners. Since we wished to study satisfaction with a typical bus journey, to avoid short

20 connecting trips or excessively long trips, we excluded respondents with travel times below 10

21 minutes and above 70 minutes, reducing the dataset to 43,552 entries. Moreover, because of the

222012 Summer Olympic games and the influx of tourists and athletes, as well as the added traffic

23 in London (Sumner, 2012), we removed respondents from 25 July until 14 August 2012

24 inclusive. Finally, we removed entries with incomplete, partial, or 'do not know' answers leaving

2528,375 respondents. We removed riders that had used next-arrival information (except for

26 electronic signage/countdown at the bus stop/shelter) as these riders may have different

27 satisfaction criteria (Carrel, Mishalani, et al., 2015; Tang \& Thakuriah, 2011). Moreover, the

28 questions pertaining to next-arrival information became more detailed in 2014, so we included

29 only respondents that were asked simply whether there was an electronic countdown clock at the

30 stop/shelter (and if used or not), as well as respondents that answered as not using any next-

31 arrival information. In addition, this subgroup will be addressed in future studies. The dataset 
1 used before differentiating different subgroups included 22,569 respondents, with 3,603 from

$22010,15,944$ from 2011, 13,326 from 2012, 14,659 from 2013, 14,436 from 2014, and 3,538

3 from 2015. Next, we divided riders into three subgroups of interest: regular, encumbered, and

4 disabled riders.

5 'Regular riders' are respondents with no encumbrances (i.e., no shopping bags, baby

6 prams or small children, or large items or suitcase) or disabilities, for a total of 16,830

7 respondents. Note, regular riders in this paper are not defined by regularity of usage, as in

8 previous research (Krizek \& El-Geneidy, 2007). 'Encumbered riders' excludes riders with any

9 disabilities, and includes respondents that were carrying the following: suitcase/heavy luggage

10 and/or large or awkward item; shopping bags and/or shopping trolley; or small child/baby in

11 arms and/or baby buggy/pushchair/pram. We excluded respondents that were carrying multiple

12 encumbrances (to ease the interpretation of model results resulting from excessive dummy

13 interaction variables) for a total of 4,136 respondents. For riders with disabilities ('disabled

14 riders'), we included only riders with mobility disabilities (including age-related mobility

15 disabilities), and/or with hearing disabilities, and/or with visual disabilities; respondents may

16 have had more than one of these disabilities. This subgroup excluded respondents with

17 encumbrances for a total of 555 respondents.

18 Although SEM is common in the transit satisfaction literature, structural equation models

19 are nevertheless difficult to interpret because of how different variables work together to

20 influence unobserved variables. In addition, whether transit agencies derive added benefit from

21 complicated models is questionable. In the present paper, we used logistic modeling to determine

22 how different criteria impact the odds that a bus rider will be satisfied or not. The dependent

23 variable of interest was derived from the question on overall satisfaction, rated from 0 to 10 . To

24 convert these ratings into discrete binary variables, we converted ratings of 6 and below to 0

25 (dissatisfied) and 7 and above as 1 (satisfied). We chose this cut-off because the survey

26 interviewers were instructed to follow-up satisfaction questions rated 6 or below on topics such

27 as satisfaction with ride smoothness, interior cleanliness, etc., to determine the reasons for

28 respondent dissatisfaction (“Why were you not particularly satisfied with...?”). We kept

29 satisfaction ratings on the various components as continuous variables, and combined similar

30 questions based on a factor analysis (discussed below), confirmed by how the questions were 
1 grouped in the questionnaire. Other variables, such as the presence of a bus shelter or familiarity

2 with the bus route, were converted to dummy variables for inclusion in the models.

\section{Principal Component Analysis}

5 Given the large set of questions that could be included in the models based on theory and the

6 high levels of correlations between some of the variables, it was difficult to select which

7 questions to include in the model. Applying a principle component analysis (factor analysis) to a

8 set of survey questions and including the factor loadings as independent variables is one way to

9 bypass these issues and has been used in past literature (Damant-Sirois \& El-Geneidy, 2015;

10 Hong \& Chen, 2014). The analysis included questions related to satisfaction with the bus

11 stop/shelter, the different components of the ride, and the different components of the bus itself.

12 Table 1 presents the grouping results, the weights of different components, and the name of each

13 factor component. 
TABLE 1 Results from the Principle Component Analysis

\begin{tabular}{|c|c|c|}
\hline Component & Question & Loading \\
\hline \multirow{4}{*}{ 1. Satisfaction with ride quality } & $\begin{array}{l}\text { Satisfaction with driver's behavior and } \\
\text { attitude to you }\end{array}$ & 0.725 \\
\hline & $\begin{array}{l}\text { Satisfaction with your personal safety } \\
\text { during the bus journey }\end{array}$ & 0.717 \\
\hline & $\begin{array}{l}\text { Satisfaction with the ease of getting on } \\
\text { and off this bus }\end{array}$ & 0.683 \\
\hline & $\begin{array}{l}\text { Satisfaction with the smoothness and } \\
\text { freedom from jolting during your } \\
\text { journey }\end{array}$ & 0.575 \\
\hline \multirow{3}{*}{ 2. Satisfaction with the bus exterior } & $\begin{array}{l}\text { Satisfaction with the state of repair of } \\
\text { the outside of the bus }\end{array}$ & 0.781 \\
\hline & $\begin{array}{l}\text { Satisfaction with the cleanliness and } \\
\text { freedom from graffiti of the outside of } \\
\text { the bus }\end{array}$ & 0.773 \\
\hline & $\begin{array}{l}\text { Satisfaction with the information } \\
\text { provided on the outside of the bus }\end{array}$ & 0.693 \\
\hline \multirow{4}{*}{$\begin{array}{l}\text { 3. Satisfaction with the waiting } \\
\text { area }\end{array}$} & Satisfaction with the freedom from litter & 0.798 \\
\hline & $\begin{array}{l}\text { Satisfaction with the cleanliness and } \\
\text { freedom from graffiti }\end{array}$ & 0.764 \\
\hline & Satisfaction with the state of repair & 0.688 \\
\hline & Satisfaction with your personal safety & 0.628 \\
\hline \multirow{5}{*}{$\begin{array}{l}\text { 4. Satisfaction with interior } \\
\text { comfort }\end{array}$} & $\begin{array}{l}\text { Satisfaction with the cleanliness and } \\
\text { freedom from litter inside the bus }\end{array}$ & 0.729 \\
\hline & $\begin{array}{l}\text { Satisfaction with your comfort inside the } \\
\text { bus }\end{array}$ & 0.669 \\
\hline & $\begin{array}{l}\text { Satisfaction with the state of repair } \\
\text { inside the bus }\end{array}$ & 0.607 \\
\hline & $\begin{array}{l}\text { Satisfaction with the level of crowding } \\
\text { inside the bus }\end{array}$ & 0.514 \\
\hline & $\begin{array}{l}\text { Satisfaction with the notices and other } \\
\text { information provided inside the bus }\end{array}$ & 0.450 \\
\hline
\end{tabular}

Four distinct components appear. The first deals with the quality of the on-board ride or experience, including driver's behavior and driving, and personal safety, and explains $18.49 \%$ of the variance. The second component pertains to satisfaction with appearance of the bus exterior and explains $17.96 \%$ of the variance, while the third component focuses on the appearance and experience at the waiting area (bus stop and/or shelter) and explains $16.65 \%$ of the variance. The

9 fourth component focuses on satisfaction of the interior comfort of the bus, including cleanliness

10 and crowding and explains the $15.19 \%$ of the variance. The factor loadings were used in the

11 logistic regression models, and their averages are presented in Table 1.

12

\section{RESULTS}


1 The average values for the variables shown in Table 2 demonstrate that all subgroups had similar

2 percentages of satisfied respondents, and slightly more disabled riders were satisfied with overall

3 service (regular, 87\%, encumbered, 87\%, and disabled, 90\%). Average travel times were also

4 similar, about 18 to19 minutes for each subgroup. In general, encumbered riders gave slightly

5 higher satisfaction scores on waiting time, length of journey time, reliability and information at

6 the bus stop than regular riders, and these scores were again slightly higher for disabled riders

7 (Table 2). Table 1 also shows the average values of the factor loadings for each groups of riders

8 derived from the principle component analysis.

\section{TABLE 2 Means of Variables in Overall Satisfaction Models}

"Thinking about this particular bus journey you have just made, starting at the bus stop, how satisfied are you on a scale of 0 to 10 (where 10 is extremely satisfied and 0 is extremely dissatisfied) with the overall service you experienced today?" 0-10 scale converted 0-6 to 0, dissatisfied, and 7-10 to 1, satisfied

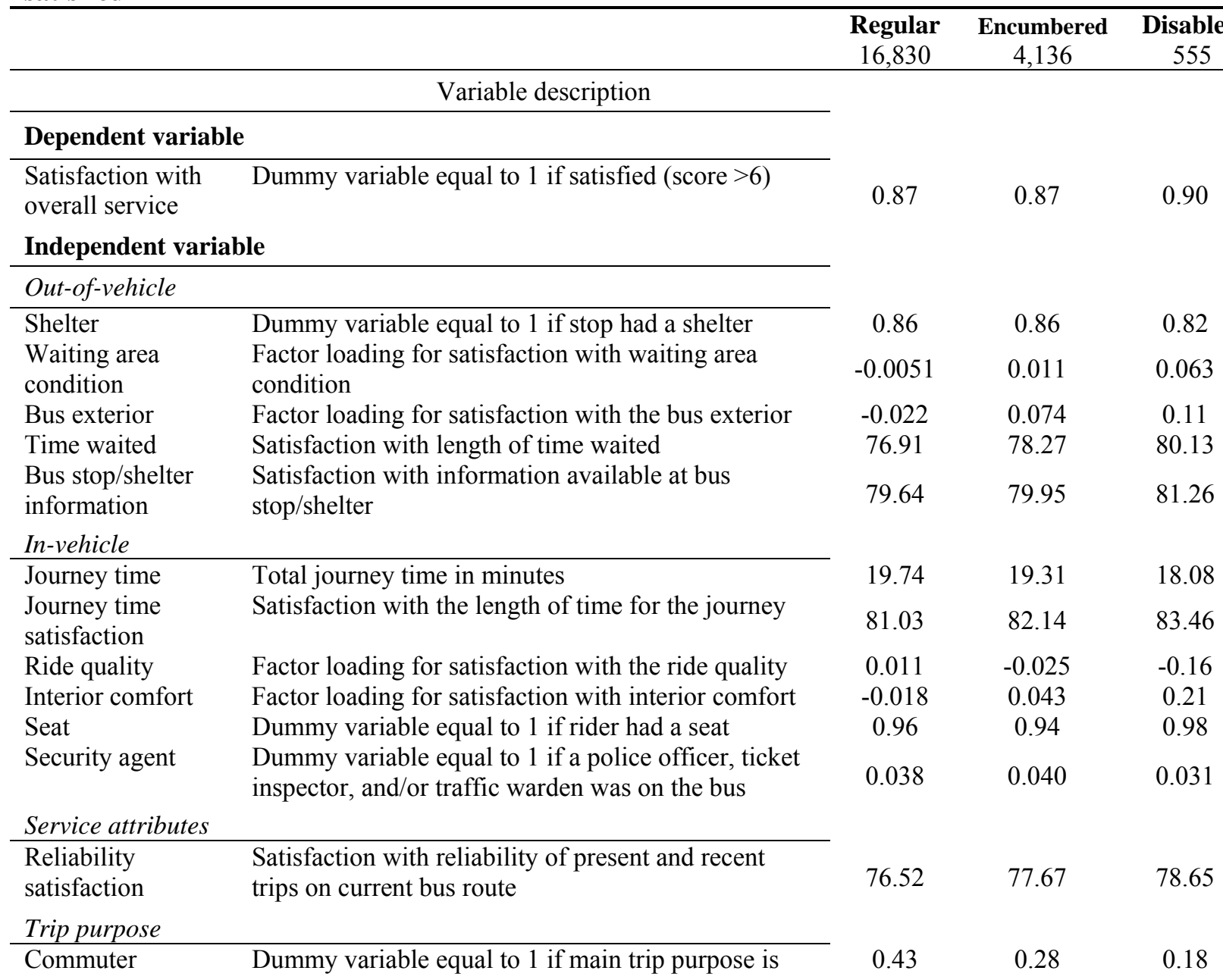




\begin{tabular}{|c|c|c|c|c|}
\hline \multirow[b]{2}{*}{ Education } & \multirow[b]{2}{*}{$\begin{array}{l}\text { commuting (including employer's business) } \\
\text { Dummy variable equal to } 1 \text { if main trip purpose is } \\
\text { for education }\end{array}$} & \multirow[b]{2}{*}{0.12} & \multirow[b]{2}{*}{0.061} & \multirow[b]{2}{*}{0.023} \\
\hline & & & & \\
\hline Shopping & $\begin{array}{l}\text { Dummy variable equal to } 1 \text { if main trip purpose is } \\
\text { shopping }\end{array}$ & 0.15 & 0.38 & 0.34 \\
\hline Leisure & $\begin{array}{l}\text { Dummy variable equal to } 1 \text { if main trip purpose is } \\
\text { visiting friends/relatives, leisure, personal business } \\
\text { or holiday/sightseeing }\end{array}$ & 0.29 & 0.26 & 0.46 \\
\hline Child-related & $\begin{array}{l}\text { Dummy variable equal to } 1 \text { if main trip purpose is } \\
\text { taking or collecting a child }\end{array}$ & 0.0092 & 0.025 & - \\
\hline \multicolumn{5}{|c|}{ Personal attributes } \\
\hline White & $\begin{array}{l}\text { Dummy variable equal to } 1 \text { if respondent is White } \\
\text { (British, Irish, other) }\end{array}$ & 0.54 & 0.62 & 0.78 \\
\hline Mixed race & $\begin{array}{l}\text { Dummy variable equal to } 1 \text { if respondent is Mixed } \\
\text { race (White and Black Caribbean, White and Black } \\
\text { African, White and Asian, any other mixed } \\
\text { background) }\end{array}$ & 0.031 & 0.022 & 0.011 \\
\hline Asian & $\begin{array}{l}\text { Dummy variable equal to } 1 \text { if respondent is } \\
\text { Asian/Asian British (Indian, Pakistani, } \\
\text { Bangladeshi, Chinese, other) }\end{array}$ & 0.25 & 0.17 & 0.083 \\
\hline Black & $\begin{array}{l}\text { Dummy variable equal to } 1 \text { if respondent is } \\
\text { Black/Black British (Caribbean, African, other) }\end{array}$ & 0.17 & 0.18 & 0.12 \\
\hline Male & Dummy variable equal to 1 if respondent is male & 0.53 & 0.33 & 0.50 \\
\hline Familiar & $\begin{array}{l}\text { Dummy variable equal to } 1 \text { if respondent is very or } \\
\text { quite familiar with the journey }\end{array}$ & 0.98 & 0.98 & - \\
\hline \multicolumn{5}{|l|}{ Encumbered } \\
\hline Large item & $\begin{array}{l}\text { Dummy variable equal to } 1 \text { if the respondent is } \\
\text { carrying a suitcase/heavy luggage and/or large or } \\
\text { awkward item }\end{array}$ & n.a. & 0.16 & n.a. \\
\hline Shopping & $\begin{array}{l}\text { Dummy variable equal to } 1 \text { if the respondent is } \\
\text { carrying shopping bags and/or shopping trolley }\end{array}$ & n.a. & 0.72 & n.a. \\
\hline Child & $\begin{array}{l}\text { Dummy variable equal to } 1 \text { if the respondent is } \\
\text { carrying a small child/baby in arms and/or baby } \\
\text { buggy/pushchair/pram }\end{array}$ & n.a. & 0.12 & n.a. \\
\hline \multicolumn{5}{|l|}{ Disability } \\
\hline Mobility & $\begin{array}{l}\text { Dummy variable equal to } 1 \text { if the respondent has a } \\
\text { mobility impairment (including age-related) }\end{array}$ & n.a. & n.a. & 0.83 \\
\hline Visual & $\begin{array}{l}\text { Dummy variable equal to } 1 \text { if the respondent has a } \\
\text { visual impairment }\end{array}$ & n.a. & n.a. & 0.11 \\
\hline Hearing & $\begin{array}{l}\text { Dummy variable equal to } 1 \text { if the respondent has a } \\
\text { hearing impairment }\end{array}$ & n.a. & n.a. & 0.09 \\
\hline \multicolumn{5}{|c|}{$\begin{array}{l}\text { n.a. indicates variables not included in a specific subgroup; - indicates variables with too few entries to be includec } \\
\text { in the model }\end{array}$} \\
\hline
\end{tabular}


TABLE 3 Results of Logistic Regression Models

2 Satisfied with overall service experience on the particular bus journey just made

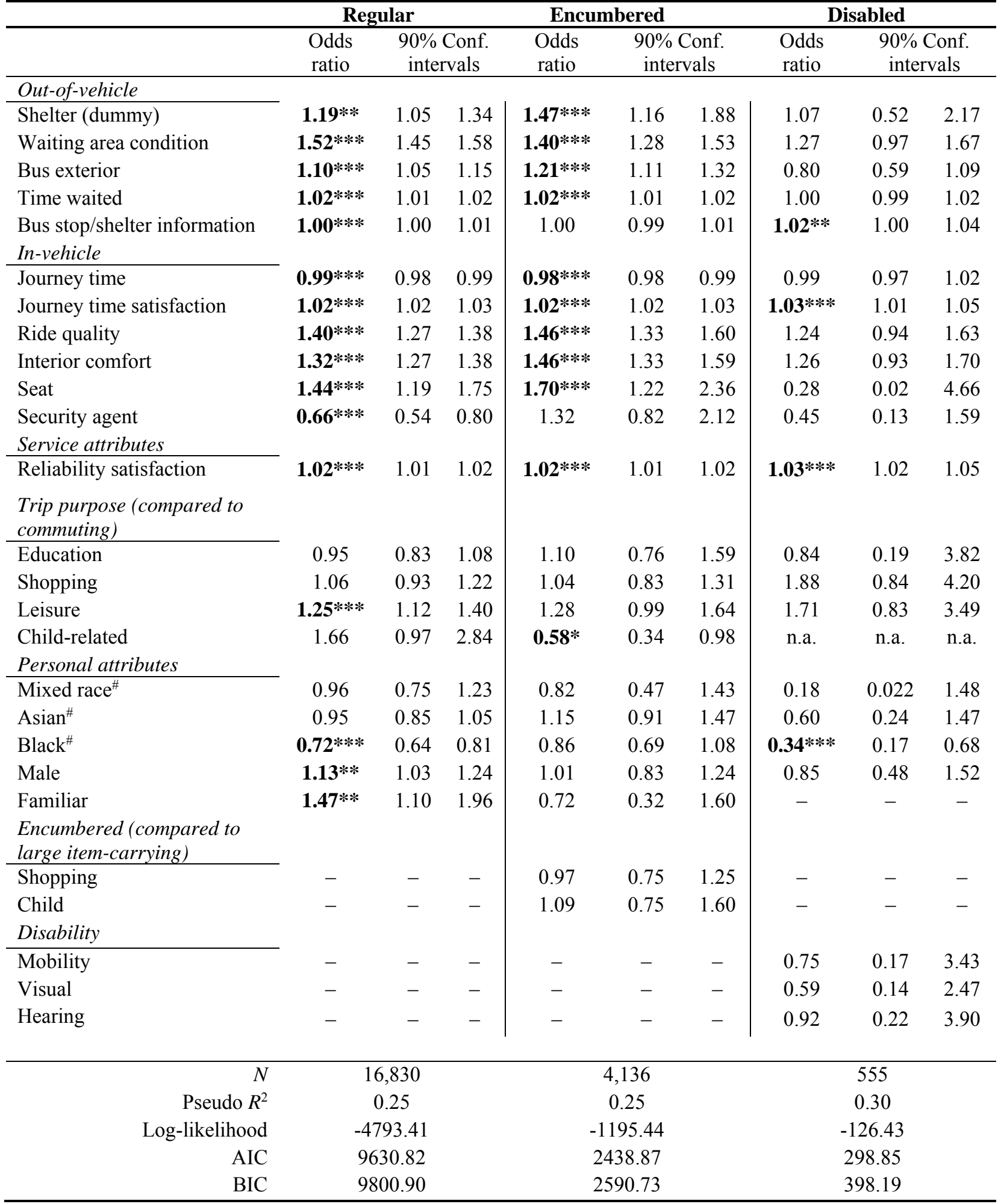

3 - indicates variables not included in a specific subgroup; n.a. indicates variables with too few entries to be included 4 in the model; " ${ }^{*}$ compared to White riders; bold indicates statistically significant variables at ${ }^{*} P<0.10,{ }^{* *} P<0.05$, 
Table 3 presents the odds ratios and 90\% confidence intervals for the three models. For out-of-vehicle variables, having a bus shelter increases the likelihood of being satisfied overall by 1.19 times for regular users, but by 1.47 times for encumbered users, while disabled riders are not affected by the presence of shelters. Having a bus shelter to sit in and rest encumbrances is clearly a priority for encumbered riders. Relatedly, increasing satisfaction of regular users with the waiting area (stop and/or shelter) will increase overall satisfaction by 1.52 times, while encumbered users are 1.40 times more likely to be satisfied overall; this variable is nonsignificant for disabled riders. This finding shows that in addition to having a shelter, a strong predictor of satisfaction is a clean, safe, and well-maintained waiting area that will benefit encumbered riders and also regular riders. The exterior condition of the bus has less of an impact, as increasing satisfaction with the bus exterior will increase the likelihood of overall satisfaction for regular riders by 1.10 times and 1.21 times for encumbered riders, while the bus exterior has no impact on satisfaction of riders with disabilities. This finding is similar to previous research stating that a bus exterior that is well-maintained is appreciated but not a priority compared to a comfortable waiting area (Yoh, Iseki, Smart, \& Taylor, 2011).

Greater satisfaction with waiting time increases the likelihood of overall satisfaction by 1.02 times for both regular and encumbered riders, but not for disabled riders. Satisfaction with information about the bus route and schedule at the stop/shelter (including electronic next-arrival board) increases the likelihood of overall satisfaction for disabled riders by 1.02 times, while it has a marginal impact on regular users and was non-significant for encumbered riders. This heterogeneous affect on the different subgroups is likely due to next-arrival information access; perhaps disabled riders have less access to next-arrival information on devices like smartphones and thus rely most on information at the bus stop. Taken together, for out-of-vehicle characteristics, overall satisfaction of disabled riders is only influenced by information at the stop/shelter, while encumbered and regular riders' satisfaction overall depends largely on the presence of a shelter and the condition of the waiting area.

Total journey time significantly impacts satisfaction for regular and encumbered riders, as every minute of travel time decreases the odds of regular riders being satisfied by 1.01 and by 1.02 times for encumbered riders. Journey time is not significant for disabled riders. Nevertheless, subjective satisfaction with journey time is a significant variable for overall 
1 satisfaction for all three subgroups. Increasing satisfaction with journey time increases the

2 likelihood of overall satisfaction by 1.02 times for regular and encumbered riders, and 1.03 times

3 for disabled riders. Our finding is consistent with a large amount of literature demonstrating the

4 importance of journey time in transit satisfaction (Carrel, Mishalani, et al., 2015; Schmitt, Currie,

5 \& Delbosc, 2013; Zhao et al., 2014), and shows that all subgroups studied here value rapid trips.

More importantly, increasing satisfaction with ride quality — which relates to driver

7 behavior, smoothness of the ride, and personal safety - for regular riders will increase their

8 likelihood of overall satisfaction by 1.40 times and 1.46 times for encumbered riders. Greater

9 satisfaction with comfort during the ride, including satisfaction with cleanliness of the bus

10 interior, level of crowding, and information on the bus, increases the likelihood of overall

11 satisfaction by 1.32 times for regular riders and 1.46 times for encumbered riders. None of the

12 previously discussed variables were statistically significant for disabled riders. These findings

13 recapitulate previous work showing that the level of crowding is a key determinant of

14 satisfaction and route usage (Imaz et al., 2015; McMullan \& Majumdar, 2012). Associated with

15 crowding is the ability to find a seat, and having a seat will increase the likelihood of overall

16 satisfaction for regular riders by 1.44 times and 1.70 times for encumbered riders. Interestingly,

17 having a seat does not influence the satisfaction of riders with disabilities, and since most riders

18 with disabilities had a seat, our models demonstrate the effectiveness of priority seating as a

19 policy. Curiously, for regular riders, the on-board presence of a security agent will decrease the

20 odds of overall satisfaction by 1.52 times. While safety was included in the 'ride quality' and

21 'waiting area' variables, safety with transit use seems to depend mainly on an individual's trust

22 of others and their neighborhood (Delbosc \& Currie, 2012b). A conspicuous security agent, on

23 the other hand, may cause antagonism.

24 Reliability is a key indicator important to both bus operators and riders (Carrel, Lau,

25 Mishalani, Sengupta, \& Walker, 2015; Eboli \& Mazzulla, 2011; Hensher \& Stanley, 2003;

26 Tyrinopoulos \& Antoniou, 2008; Yoh et al., 2011), and we confirm that all subgroups in our

27 study place importance on reliability. Increasing satisfaction with reliability of the bus route will

28 increase the overall likelihood of satisfaction by 1.02 times for regular and encumbered riders,

29 and 1.03 times for disabled riders. Therefore, all riders value reliability, and for in-vehicle

30 features, having a seat is most important for regular and encumbered riders, but satisfaction with

31 journey time is most important for disabled riders. 
Regarding trip purpose, compared to commuting, regular riders traveling for personal reasons like visiting friends and family will be 1.25 times more likely to be satisfied with their trip. Interestingly, encumbered riders on child-related trips will be 1.72 times less likely to be satisfied with their trip compared to encumbered commuters. This finding highlights that traveling with children may be a stressful experience, and transit agencies should make journeys as convenient as possible to encourage riders with children to use transit, like providing priority seating for parents with small children as well as bus shelters. riders who are Black are 1.39 times and 2.94 times, respectively, less likely to be satisfied with their trip. Our finding lends credence to the potential differences in preferences for transit

11 qualities by race (Iseki \& Smart, 2012). Regular riders who are men are 1.13 times more likely to

12 be overall satisfied, demonstrating gender differences which have been more tenuous in past

13 literature (Carrel, Mishalani, et al., 2015; Iseki \& Smart, 2012). Regular riders who are familiar

14 with their journey are 1.47 times more likely to be satisfied overall, corroborating a recent study

15 that showed how unfamiliar riders develop negative views toward transit upon first usage

16 (Schmitt et al., 2013). Therefore, transit agencies could employ advertisement campaigns to

17 promote the benefits of transit to a large population, in an effort to capture infrequent users

18 (Krizek \& El-Geneidy, 2007).

None of the specific encumbrance or disability variables were significant (Table 3), suggesting that encumbered and disabled riders, in our models at least, are comparable regardless

21 of encumbrance or disability. However, this is probably artificial, since a bus rider with a hearing

22 impairment will likely have different struggles compared to a bus rider with a mobility

23 impairment. Future work should analyze a larger cohort of riders with different disabilities using 24 regular transit.

The models for regular and encumbered riders explain approximately $25 \%$ of the

26 variance in overall satisfaction, while the model for disabled riders explains approximately $30 \%$.

27 Our models are comparable in explanatory power to other travel satisfaction models (Collantes

28 \& Mokhtarian, 2007; Iseki \& Smart, 2012; St-Louis et al., 2014). Finally, the log-likelihood tests

29 reveal that the models for encumbered and disabled riders have better data fits than the model for 30 regular riders. 


\section{DISCUSSION AND CONCLUSIONS}

2 In this study, we used a large-scale bus satisfaction survey to determine how overall satisfaction

of regular riders, encumbered riders, and riders with disabilities is based on different components of the journey. Our work sheds light on how disabled riders view regular bus services, a topic that has received little previous attention. Moreover, we also analyzed encumbered riders to learn about their satisfaction with different attributes. While regular and encumbered riders have similar concerns suggesting that these groups are comparable, few variables were of significance

8 for riders with disabilities. This suggests that disabled riders likely have larger concerns than the appearance of a bus, for example, and prioritize a reliable and speedy journey.

For regular riders, satisfaction with the waiting area is an important quality, echoing

11 previous work in different cities (de Oña et al., 2013; Weinstein, 2000). Our work also uncovers

12 important policy targets that will not only improve overall satisfaction for all riders, but as well

13 for subgroups of riders who have vulnerabilities, be they a physical disability or because they

14 rely on transit for child-related or shopping purposes (Delbosc \& Currie, 2011, 2012a).

15 Importantly, the presence of a bus shelter increases the odds of overall satisfaction the most for

16 encumbered riders, suggesting that to satisfy riders with children or shopping bags, an important

17 feature to provide is a well-maintained bus shelter where they can sit or place their bags safely,

18 especially in a city like London that is well-known for its rainy seasons. Therefore, if a transit

19 agency wishes to increase ridership for shopping trips, then supplying bus shelters would be an

20 appropriate strategy. Riders with disabilities are more likely to be satisfied overall if they are

21 satisfied with information at the bus stop, but this variable is non-significant for encumbered

22 riders and has very little impact of the satisfaction of regular riders. Perhaps a lack of access to

23 other forms of next-arrival information increases the reliance of disabled riders on information at

24 a stop, while other riders will check information elsewhere. For visually impaired riders

25 specifically, having access to audible cues or schedules, as well as personalized services or

26 training (Hunter-Zaworski \& Hron, 1999) may increase their satisfaction and autonomy.

27 Therefore, agencies should ensure up-to-date information and functional next-arrival boards.

28 Another strategy could be to provide more space for pushchairs or large bags to ease the journeys

29 of encumbered riders.

30 In-vehicle travel time and reliability are important variables leading to satisfaction in

31 many studies (Carrel, Mishalani, et al., 2015; Habib et al., 2011; Iseki \& Smart, 2012), and we 
1 confirm this for all subgroups in our study. Future work should also examine how transfers affect

2 the subgroups we identified here, since the format of the question in the present survey was

3 complex and were difficult to control for. We also have a hint at the psychological impacts on

4 trip satisfaction (St-Louis et al., 2014); regular riders traveling for personal business or leisure

5 are more likely to be satisfied than commuters, while encumbered riders on child-related travel

6 are less likely to be satisfied than commuters with their trip. These observations require more

7 detailed analysis through in-depth interviews to understand the reasons for these discrepancies in

8 the levels of satisfaction. Finally, regular riders who are men are more likely to be satisfied

9 overall, although future work could parse the genders to determine which components may be

10 important to men and women equally, since previous work was inconclusive (Carrel, Mishalani,

11 et al., 2015; Iseki \& Smart, 2012).

12 While our study has addressed how riders with disabilities and encumbrances value

13 different aspects of bus services, future work could split these groups into irregular and regular

14 riders based on usage (Krizek \& El-Geneidy, 2007), as well as into captive, choice, and captive-

15 by-choice categories (van Lierop \& El-Geneidy, 2014). It would thus be important that future

16 surveys include questions about car availability. For disabled riders using regular transit, follow-

17 up surveys about specific problems they encounter may help improve bus design for these

18 vulnerable users (Bareria et al., 2012). Lastly, people filter their experiences through their

19 personal values, and subjective well-being is an important factor for transit satisfaction (Carrel,

20 Mishalani, et al., 2015; Eboli \& Mazzulla, 2011). Bearing this in mind, future transit customer

21 satisfaction surveys should query general well-being and mood.

\section{ACKNOWLEDGMENTS}

24 We wish to thank Kathryn Jones, John Barry, and Alex Phillips from TfL for the survey data and 25 support, and Charis Loong for critical reading of this manuscript. Also we would like to thank 26 the anonymous reviewers for their feedback on the earlier versions of the manuscript. This work 27 was supported by a research grant from the Natural Sciences and Engineering Research Council 28 of Canada. 


\section{References}

3 Bareria, P., D’Souza, C., Lenker, J., Paquet, V., \& Steinfeld, E. (2012). Performance of visually

Board, T. R. (1999). A Handbook for Measuring Customer Satisfaction and Service Quality. impaired users during simulated boarding and alighting on low-floor buses. Proceedings of the Human Factors and Ergonomics Society Annual Meeting, 56(1), 656-660. doi:10.1177/1071181312561137 Retrieved from Washington, D.C.:

Carrel, A., Lau, P. S. C., Mishalani, R. G., Sengupta, R., \& Walker, J. L. (2015). Quantifying transit travel experiences from the users' perspective with high-resolution smartphone and vehicle location data: Methodologies, validation, and example analyses. Transportation Research Part C: Emerging Technologies, Epub ahead of print. doi:http://dx.doi.org/10.1016/j.trc.2015.03.021

Carrel, A., Mishalani, R. G., Sengupta, R., \& Walker, J. L. (2015). In pursuit of the happy transit rider: Dissecting satisfaction using daily surveys and tracking data. Working paper.

Collantes, G. O., \& Mokhtarian, P. L. (2007). Subjective assessments of personal mobility: What makes the difference between a little and a lot? Transport Policy, 14(3), 181-192. doi:http://dx.doi.org/10.1016/j.tranpol.2006.12.002

Damant-Sirois, G., \& El-Geneidy, A. (2015). Who cycles more? Determining cycling frequency through a segmentation approach in Montreal, Canada. Transportation Research Part A: Policy and Practice, 77, 113-125. doi:http://dx.doi.org/10.1016/j.tra.2015.03.028

de Oña, J., de Oña, R., Eboli, L., \& Mazzulla, G. (2013). Perceived service quality in bus transit service: A structural equation approach. Transport Policy, 29, 219-226. doi:http://dx.doi.org/10.1016/j.tranpol.2013.07.001

Delbosc, A., \& Currie, G. (2011). Transport problems that matter - social and psychological links to transport disadvantage. Journal of Transport Geography, 19(1), 170-178. doi:http://dx.doi.org/10.1016/j.jtrangeo.2010.01.003

Delbosc, A., \& Currie, G. (2012a). Choice and disadvantage in low-car ownership households. Transport Policy, 23, 8-14. doi:http://dx.doi.org/10.1016/j.tranpol.2012.06.006 
1 Delbosc, A., \& Currie, G. (2012b). Modelling the causes and impacts of personal safety

2 perceptions on public transport ridership. Transport Policy, 24, 302-309. doi:http://dx.doi.org/10.1016/j.tranpol.2012.09.009

Denson, C. R. (2000). Public sector transportation for people with disabilities: A satisfaction survey. Journal of Rehabilitation, 66(3), 29-37. Retrieved from

Eboli, L., \& Mazzulla, G. (2007). Service quality attributes affecting customer satisfaction for bus transit. Transportation, 10(3), 21-34. Retrieved from http://scholarcommons.usf.edu/jpt/vol10/iss3/2/

Eboli, L., \& Mazzulla, G. (2011). A methodology for evaluating transit service quality based on subjective and objective measures from the passenger's point of view. Transport Policy, 18(1), 172-181. doi:http://dx.doi.org/10.1016/j.tranpol.2010.07.007

Habib, K. M. N., Kattan, L., \& Islam, M. T. (2011). Model of personal attitudes towards transit service quality. Journal of Advanced Transportation, 45(4), 271-285. doi:10.1002/atr.106

Hensher, D. A., \& Stanley, J. (2003). Performance-based quality contracts in bus service provision. Transportation Research Part A, 37, 519-538.

Hong, J., \& Chen, C. (2014). The role of the built environment on perceived safety from crime and walking: Examining direct and indirect impacts. Transportation, 41(6), 1171-1185. doi:10.1007/s 11116-014-9535-4

Hunter-Zaworski, K., \& Hron, M. L. (1999). Bus accessibility for people with sensory disabilities. Transportation Research Record: Journal of the Transportation Research Board, 1671, 40-47. doi:doi:10.3141/1671-07

Hunter-Zaworski, K., \& Zaworski, J. (1999). Auto-engaging mobility-aid securement systems and low-floor buses. Transportation Research Record: Journal of the Transportation Research Board, 1671, 27-33. doi:doi:10.3141/1671-05

Imaz, A., Nurul Habib, K. M., Shalaby, A., \& Idris, A. O. (2015). Investigating the factors affecting transit user loyalty. Public Transport, 7(1), 39-60. doi:10.1007/s12469-0140088-x

Iseki, H., \& Smart, M. (2012). How do people perceive service attributes at transit facilities? Transportation Research Record: Journal of the Transportation Research Board, 2274, 164-174. doi:doi:10.3141/2274-18 
1 Jin, X., Beimborn, E., \& Greenwald, M. (2005). Impacts of accessibility, connectivity and mode captivity on transit choice. Retrieved from Milwaukee, WI:

Koushki, P. A., Al-Saleh, O. I., \& Al-Lumaia, M. (2003). On management's awareness of transit passenger needs. Transport Policy, 10(1), 17-26. doi:http://dx.doi.org/10.1016/S0967$\underline{070 X(02) 00025-2}$

Krizek, K., \& El-Geneidy, A. (2007). Segmenting preferences and habits of transit users and non-users. Journal of Public Transportation, 10(3), 71-94. Retrieved from http:/tram.mcgill.ca/Research/Publications/segmenting_prefernce.pdf

Lai, W. T., \& Chen, C. F. (2011). Behavioral intentions of public transit passengers-The roles of service quality, perceived value, satisfaction and involvement. Transport Policy, 18(2), 318-325. doi:http://dx.doi.org/10.1016/j.tranpol.2010.09.003

London, T. f. (n.d.-a). Buses. Retrieved from https://tfl.gov.uk/corporate/about-tfl/what-we-

14 London, T. f. (n.d.-b). Dial-a-Ride - Membership. Retrieved from https://tfl.gov.uk/modes/diala-ride/membership?intcmp $=4002$

Lubin, A., \& Deka, D. (2012). Role of public transportation as job access mode: Lessons from survey of people with disabilities in New Jersey. Transportation Research Record: Journal of the Transportation Research Board, 2277, 90-97. doi:doi:10.3141/2277-11

Marković, N., Milinković, S., Schonfeld, P., \& Drobnjak, Z. (2013). Planning dial-a-ride services. Transportation Research Record, 2353, 120-127. Retrieved from http://www.scopus.com/record/display.url?eid=2-s2.0-

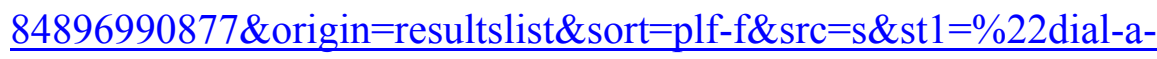
$\underline{\text { ride } \% 22+A N D+\text { social\&st2=\&sid=164AEA16DFC6F2AC1D293E4967AD4690.I0QkgbI }}$ jGqqLQ4Nw7dqZ4A\%3a10\&sot=b\&sdt=b\&sl=39\&s=TITLE-ABS-KEY\%28\%22dial-a-

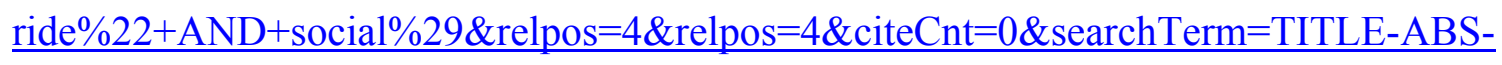
KEY\%28\%5C\%26quot\%3Bdial-a-ride\%5C\%26quot\%3B+AND+social\%29

McMullan, A., \& Majumdar, A. (2012). Assessing the impact of travel path choice on London's rail network using an automatic fare collection system. Transportation Research Record: Journal of the Transportation Research Board, 2274, 154-163. doi:doi:10.3141/2274-17

MTA. (n.d.). MTA/New York City Transit - Paratransit - How to Reserve a Trip. Retrieved from http://web.mta.info/nyct/paratran/guide.htm - reserve 
1 Paquette, J., Cordeau, J.-F., \& Laporte, G. (2009). Quality of service in dial-a-ride operations. Computers \& Industrial Engineering, 56(4), 1721-1734. doi:http://dx.doi.org/10.1016/j.cie.2008.07.005

Schmitt, L., Currie, G., \& Delbosc, A. (2013). Measuring the impact of unfamiliar transit travel using a university access survey. Transport Policy, 30, 301-307. doi:http://dx.doi.org/10.1016/j.tranpol.2013.09.003

Shiftan, Y., Outwater, M. L., \& Zhou, Y. (2008). Transit market research using structural equation modeling and attitudinal market segmentation. Transport Policy, 15(3), 186195. doi:http://dx.doi.org/10.1016/j.tranpol.2008.03.002

St-Louis, E., Manaugh, K., van Lierop, D., \& El-Geneidy, A. (2014). The happy commuter: A comparison of commuter satisfaction across modes. Transportation Research Part F: Psychology and Behaviour, 26, 160-170. Retrieved from http://www.sciencedirect.com/science/article/pii/S1369847814001107

Stuart, K., Mednick, M., \& Bockman, J. (2000). Structural equation model of customer satisfaction for the New York City subway system. Transportation Research Record: Journal of the Transportation Research Board, 1735, 133-137. doi:doi:10.3141/1735-16

Sumner, H. (2012). Briefing: Delivering London 2012: Meeting the transport challenge. Proceedings of the ICE - Transport, 165, 237-239. http://www.icevirtuallibrary.com/content/article/10.1680/tran.12.00066 Retrieved from http://www.icevirtuallibrary.com/content/article/10.1680/tran.12.00066

Tang, L., \& Thakuriah, P. (2011). Will psychological effects of real-time transit information systems lead to ridership gain? Transportation Research Record: Journal of the Transportation Research Board, 2216, 67-74. doi:doi:10.3141/2216-08

Tyrinopoulos, Y., \& Antoniou, C. (2008). Public transit user satisfaction: Variability and policy implications. Transport Policy, 15(4), 260-272. doi:http://dx.doi.org/10.1016/j.tranpol.2008.06.002

van Lierop, D., \& El-Geneidy, A. (2014). Getting committed: A new perspective on public transit market segmentation from two Canadian cities. Paper presented at the 94th Transportation Research Board Annual Meeting, Washington, DC. 
1 Weinstein, A. (2000). Customer satisfaction among transit riders: How customers rank the relative importance of various service attributes. Transportation Research Record: Journal of the Transportation Research Board, 1735, 123-132. doi:doi:10.3141/1735-15

4 Yoh, A., Iseki, H., Smart, M., \& Taylor, B. (2011). Hate to wait: Effects of wait time on public

5 transit travelers' perceptions. Transportation Research Record: Journal of the Transportation Research Board, 2216, 116-124. doi:doi:10.3141/2216-13

7 Zhao, J., Webb, V., \& Shah, P. (2014). Customer loyalty differences between captive and choice 8 transit riders. Transportation Research Record: Journal of the Transportation Research Board, 2415, 80-88. doi:doi:10.3141/2415-09 